\section{Effects of Several Warm-Up Protocols (Static, Dynamic, No Stretching, Greek Traditional Dance) on Motor Skill Performance in Primary School Students}

\author{
Georgios Lykesas ${ }^{\mathrm{a},{ }^{*}}$, Ioannis Giossos ${ }^{\mathrm{b}}$, Dimitrios Chatzopoulos ${ }^{\mathrm{c}}$, \\ Maria Koutsoubad, Stella Douka ${ }^{e}$, Eugenia Nikolakif
}

\begin{tabular}{ll}
\hline Received: & 22 March 2020 \\
Revised: & 18 May 2020 \\
Accepted: $\quad 13$ June 2020 \\
ISSN: 1307-9298 \\
Copyright $\odot$ IEJEE \\
www.iejee.com
\end{tabular}

DOI: $10.26822 /$ iejee.2020562138

\begin{abstract}
WThe aim of the present study was to compare the effects of four warm-up protocols on agility, strength, static and dynamic flexibility in primary school students. The participants were forty-four students of a primary school (19 boys and 25 girls) and the mean age of the children was $11.7 \pm 0.47$. All of them executed, in four different days, one of the following protocols: (a) 3 minutes of jogging followed by 5 minutes of static stretching, (b) 3 minutes of jogging followed by 5 minutes of dynamic stretching, (c) 3 minutes of jogging followed by a 5 -minute break (no stretching protocol), and (d) 8 minutes of Greek traditional dances. On the completion of the protocols, the participants did the following tests: the agility shuttle run test $(4 \times 10 \mathrm{~m})$, the standing long jump test, the sit \& reach test, and the active straight leg raise test (dynamic flexibility). According to the results of the repeated measures analysis of variance (ANOVA), the protocol of static stretching showed significantly better scores on static flexibility compared to the protocols of dance and no stretching. As for the long jump, dynamic stretching produced significantly better results compared to static stretching and no stretching. Concerning dynamic flexibility, there were no significant differences between the four warm-up protocols. As for agility, the dance protocol presented significantly better results compared to static stretching. Moreover, girls performed better on the sit \& reach test compared to boys. In conclusion, the static-stretch protocol is suggested for lessons that require a maximal range of motion (flexibility). On the other hand, it seems that dynamic stretching is more suitable than the other protocols when the lesson requires lower extremity strength. Moreover, it seems that the dance protocol is suitable for lessons requiring agility. Therefore, teachers should implement different stretching protocols according to the content of the lesson.
\end{abstract}

Keywords: Warm-Up Protocols, Static Stretching, Dynamic Stretching, No Stretching, Greek Traditional Dance, Primary Education, Students

\section{Introduction}

In many countries, research is currently being undertaken in order to improve physical education (PE) curricula, as well as, the structure of PE lessons in schools (Lee et al., 2007). The same applies to warm-up, which is the preparatory part of the lesson.

Warming-up increases body temperature, improves the cooperation and coordination of the muscles, and has positive psychological effects such as enhanced readiness and mood for exercise (Bishop, 2003; Bishop, et al., 2013). Additionally, some studies support that it also helps to reduce injuries (Shellock \& Prentice, 1985; Young \& Behm, 2002). According to Bishop et al. (2003), the warm-up techniques can be broadly classified into two major categories: passive warm-up and active warmup. During passive warm-up the muscle temperature rises due to external means (sauna, diathermies), whereas active warmup, which is used during a PE lesson, involves exercise and leads to major cardiovascular changes to the organism.

Most schoolteachers follow strategies of active warm-up. During the lesson they combine light jogging, in order to raise body temperature, and stretching exercises to improve the flexibility of the joints (Young \& Behm, 2002). There are several stretching techniques such as static, ballistic, dynamic, and specialized. The general recommendations for active warm-up mention the introduction of low intensity aerobic workout (e.g. jogging), followed by static stretching (Young \& Behm, 2002). Therefore, it has been generally accepted for a long time that a static-stretching warm-up improves student performance, corrects body posture, and reduces injuries (Shellock \& Prentice, 1985).
This view seems to be supported by the research of Mayorga-Vega et al., (1994), conducted in 45 students (9-10 years old), underlining the benefits of static stretching in enhancing hamstring muscle flexibility. However, according to other research, static-stretching warm-up reduces maximal strength (McNeal \& Sands, 2003). In this particular study, 13 girls (athletes of gymnastics) were measured according to the time they remained on air during jumps after training with and without static stretching. Reduction of their time on air was observed during the jump that followed the static-stretching warm-up. Low muscle temperature is a factor that is reported to contribute in strength loss after a static-stretching warm-up (Hedrick, 2000). Static stretches also seem to be responsible for the decrease of the electrical muscle stimulation, a stretch reflex that starts responding during the eccentric phase of the stretch-shortening cycle (Winchester et al., 2008). While the reduced electrical muscle stimulation may possibly lead as well to lower ability to recruit motor units, which then decreases the production of strength (Bosco et al., 1982). In that same context, the research of Gelen (2011), after measuring a sample of 55 students who were playing basketball 3 times a week, showed that after a static-stretching warm-up the height of jump the students attained was decreased compared to the height of jump achieved after a general warm-up, without stretching.

However, other studies prove that there is neutral effect on the production of strength after static stretching. For example, Behm et al., (2004), studied the effect of warming-up, with and without static stretching, on strength production, balance, and reaction time and did not find significant differences in the production of strength. Nevertheless, their findings showed that both balance and reaction time were reduced after a static-stretching warm-up.

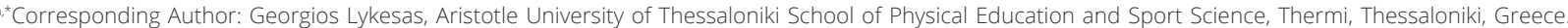
ORCID:https://orcid.org/0000-0002-1964-9075, E-mail: glykesas@phed.auth.gr loannis Giossos, ORCID:https://orcid.org/0000-0002-8145-2097,E-mail: xayiannis@gmail.com Dimitrios Chatzopoulos, ORCID:https://orcid.org/0000-0001-5069-2613,E-mail: chatzop@phed.auth.gr Maria Koutsouba, ORCID:https://orcid.org/0000-0002-2085-0622,E-mail: makouba@phed.uoa.gr Stellae Douka, ORCID:https://orcid.org/0000-0002-0018-0350,E-mail: sdouka@phed.auth.gr

fEugenia Nikolaki, E-mail: evinikolaki@gmail.com 
Over the last years, dynamic stretching that is a warm-up with dynamic workout seems to gain ground in coaches' preferences (Turki et al., 2011; Alikhajeh, 2012; Alikhajeh et al., 2012). Dynamic stretching consists of a series of low, moderate, and high intensity exercises in which both upper and lower extremities contribute and achieve stretching (Faigenbaum et al., 2006). According to many studies, dynamic stretching indeed seems to have a positive effect on strength and agility (Yamaguchi et al., 2005; Gelen, 2011). Similar positive effects of dynamic stretching have also been recorded in many studies on speed and performance improvement, generally (Fletcher, 2010; Behm \& Chaouachi, 2011). Researchers have also focused on the reasons why dynamic-stretching warmup with has a positive effect on maximal strength production. For example, the study of Yamagushi \& Ishi (2005) reports these reasons and it is assumed that the muscles' temperature rises as they are joined actively and rhythmically in order to stretch a specific muscle group during a dynamic warm-up (Yamagushi \& Ishii, 2005). An alternative interpretation is that dynamic stretching may cause a meta-stimulative lift, in other words, a temporary improvement in muscular performance after a previous contraction.

This point is also supported by the research findings of Chatzopoulos et al., (2014) who compared the effects of the three different protocols on balance, agility, reaction time, and movement time during upper-extremity movements. The sample of this research was 31 student-athletes, boys and girls. The three protocols consisted of (a) 3 minutes of light jogging followed by 7 minutes of static stretching (SS), (b) 3 minutes of light jogging followed by 7 minutes of dynamic stretching (DS) and (c) 3 minutes of jogging followed by a 7-minute break (LS). According to these research results, static stretching had a negative effect on balance, agility, and movement time compared to dynamic stretching. Similar findings were produced by the research of Patrick Troumbley (2010), in which the two warm-up protocols of dynamic and static stretching were applied to 14 men and 10 women, and their effect on the time of preparation for some fast movements of agility was examined. The results showed that dynamic stretching had the fastest time of preparation for agility exercises (Troumbley, 2010).

All the aforementioned studies have focused either on athletes of different sports (Gelen, 2011) or on secondary school students (Chatzopoulos et al., 2014). Few studies have generally been realized on the effects of the different warm-up protocols, especially on PE lessons in primary education. One of these studies was the research of Coledam et al., (2012) Paludo, De Oliveira and Dos-Santos (2012), which aimed at comparing the effects of dynamic stretching to a "tag" game. There were no significant differences between the dynamic workout and the game, neither in agility nor in strength. In particular, the two warm-up models presented similar effects on shuttle run and vertical jump in children. Moreover, there was no difference between the results of boys and girls.

There are studies on dance warm-up (Morrin \& Redding, 2013; Lima et al., 2018; Sofianidis et al., 2009; Koutedakis et al., 2009; Venetsanou \& Kambas, 2010; Lykesas et al., 2016) but they refer to ballet and they mainly concern its own warmup protocols. There is no research that deals with dance as a warm-up protocol and this is due to the fact that ballet dance movements are highly demanding. Nevertheless, Greek traditional dance could be used as a warm-up protocol based on the fact that, on the one hand, there are traditional dances of moderate intensity, which have been used as a therapeutic protocol for elderly patients, on the other hand, it has been demonstrated that the Greek traditional dance can be utilized as a means to promote the motor skills of children even at a pre-school age (Lykesas, et al., 2003). Although the use of the Greek traditional dance as a warm-up protocol may well be considered valid, no empirical evidence of this possibility has been provided for the moment, and there is no research that examines this possibility. In order to examine this prospect, several warm-up protocols may be compared, including static stretching, dynamic stretching, no stretching, and the use of Greek traditional dance as a warm-up protocol.

Based on the above, the purpose of this study was to compare the effect of several warm-up protocols (static stretching, dynamic stretching, no stretching, and Greek traditional dance) on agility, strength, as well as static and dynamic flexibility in primary school students.

\section{Methodology}

The research sample comprised forty-four $(n=44)$, male and female, ( 25 girls and 19 boys) fifth and sixth graders attending a primary school of an eastern suburb in the Prefecture of Thessaloniki. Before data collection, the participants attended one orientation session, in which they were familiarized with the stretching procedures and the performance measures. After the orientation period the participants were divided randomly into four groups (10-12 children), and all performed the four protocols at a random order on four different days. The first group consisted of 11 children ( 5 boys, 6 girls), the second group of 11 children ( 5 boys and 6 girls), the third group of 11 children ( 5 boys and 6 girls), and the fourth group of 11 children ( 4 boys and 7 girls).

The protocols and the tests were administered in a randomized order to minimize potential order effects. For example, on the first day the first group performed the static stretching protocol (SS), the second group the dynamic stretching protocol (DS), etc. The warm-up protocols were executed in approximately 8 minutes. Apart from the protocol of the Greek traditional dance, all participants started the warm-up process with three minutes of light jogging followed by stretching or by a 5-minute break (no stretching protocol). The stretching protocols used in this study were consistent with general warm-up recommendations for children and are representative of a general warm-up routine used by physical education teachers (Chatzopoulos, et al. 2015; Faigenbaum, et al. 2005). After completing one of the warm-up protocols, the participants performed the test measures. The time between finishing the warm-up and beginning the testing was 2 min. A similar experimental set-up has been used by Chaouachi, et al. (2010) and Chatzopoulos, et al. (2019).

During all days the same PE teacher was responsible for all measurements. All measurements took place at the school's gym, which met the prerequisites of the same environmental conditions with stable temperature. The measurements were realized in December, during the period of two weeks, and on nonconsecutive days. In order to avoid the effect of the previous procedure, a period of two days followed each measurement. All measurements took place were realized between 9-11a.m., and all children wore tracksuits and sneakers. The students had not suffered injuries or other health problems for the last days before conducting the protocols neither during the procedure itself. They were also asked to avoid any laborious physical activity before measurements and not to consume liquids and food that could influence their performance. Each student's guardian had given his/her written consent before the students participated in this research. The study was realized according to the Code of Conduct for Research of the Aristotle University of Thessaloniki.

\section{Description of the Warm-Up Protocols}

\section{Static stretching protocol}

The three minutes of light jogging were followed by four exercises of static stretching for the muscle groups of quadriceps, back thighs, gastrocnemius muscles and adductor muscles accordingly. Every muscle group of one leg was stretched 
for thirty seconds and right after that this stretching was repeated for the same muscle group of the other leg. This sequence was executed twice.

\section{Dynamic stretching protocol}

The dynamic-stretching program consisted of seven exercises for the same muscle groups of the lower extremities in which the static stretching was applied. The dynamic stretching was executed in a $15 \mathrm{~m}$ distance. The participants performed each exercise from the one side of the $15 \mathrm{~m}$ line to the other in 10 seconds and, right after that, they returned to their initial position in other 10 seconds. There they rested for 10 seconds and continued with the following exercise. This procedure was repeated the same way one more time. The dynamic exercises were as follows: 1 ) the heels hit the buttock alternately as you move in a straight line; 2) high skipping, the knees go upwards alternately forming a 90-degree angle, while the hands being curved move back and forth in the opposite direction; 3 ) big steps forwards with a leaping movement; 4) splits with stretched legs and hands on the back; 5) side steps; 6) the Frankenstein walk, the hands are extended and the legs alternate straight and go upwards till the height of the hands; 7) walking the distance on toes and coming back walking on heels.

\section{Protocol without stretching}

The participants realized twelve minutes of light jogging.

\section{Greek traditional dance protocol}

The participants performed four Greek traditional dances forT 10 minutes (2.5 minutes each), a Macedonian dance: Syre-Syre, a Thracian dance: Trohiro, a Cretan dance: Pentozali, a dance of Epirus: Neratzia. The students moved continually during the Greek- traditional-dance protocol. The selection criteria of the above dances were the following: the different rhythmical speed (the movement regarding the parameters of time and flow), the space (as to different directions and levels), as well as, the combination of simple and complex motor skills. The order of the dances was as follows: Neratzia (slow tempo, 108 beats/min), Syre-Syre (medium tempo, 118 beats/min), Trohiro (medium tempo, 122 beats/min) and Pentozali (fast tempo, 128 beats/min).

\section{Measurements}

Upon completion of each warm-up protocol the children did the following tests:

\section{Agility shuttle run test (4X10)}

The $4 \times 10 \mathrm{~m}$ shuttle run test consisted of running back and forth between two lines, which were $10 \mathrm{~m}$ apart. The test included four sponges that were carried one by one to the different lines. At the end of each track section, the participant deposited and picked up a sponge from the line. The total distance run was $40 \mathrm{~m}$ (Ruiz et al., 2006). The performance was recorded in seconds by using a stopwatch to an accuracy of $0.1 \mathrm{~s}$.

\section{Standing long jump}

The long jump evaluated the lower extremity strength. All children performed two long jumps from a standing position and the longest jump was used for data analysis (length value $\mathrm{cm}$ ).

\section{Sit and reach}

The children were required to sit with legs together, knees straight, and feet placed against the testing box. They reached forward, as far as possible, and held this position for approximately 2 seconds. The children's score for this test was given based on the final position they reached. The children performed two trials and their best performance was used for data analysis. The test was performed according to the manual of the Eurofit handbook in a self-build construction (Adam, et al., 1988).

\section{Dynamic flexibility (active straight leg raise test)}

Hamstring flexibility was measured with an electro-goniometer $\left(0.02^{\circ}\right.$ accuracy, sampling frequency $100 \mathrm{~Hz}$, www. vernier.com) using the Active Straight Leg Raise test (Ylinen, et al., 2010). The participant laid supine with hips and knees extended. The greater trochanter was used as a reference point for the axis of the goniometer, and the lateral femoral epicondyle was the other reference point $\left(0^{\circ}\right)$. The participant lifted twice the leg, as high as possible, while keeping the knee extended with 10 seconds rest as an interval. The best score of these measurements was used for data analysis.

\section{Statistical Analysis}

Descriptive statistics indicators like the mean and the standard deviation were used while the analysis of variance (ANOVA) with repeated measures was used in order to explore the differences among the four warm-up protocols, with gender as a factor and the four warm-up protocols as repeated measures. The Bonferroni-test was used for the post-hoc analyses. Mauchly's sphericity test was used to evaluate the sphericity of the variance. The statistical significance was established at $p<.05$ and the confidence interval was $95 \%$. The statistical software used to process the data of the measures was SPSS (version 20).

\section{Results}

Agility Test

Table 1 displays the mean scores $(M)$ and the standard deviation $(S D)$ for boys and girls as far as agility is concerned.

Table 1. Mean scores (sec) and standard deviation of the test on agility (sec)

\begin{tabular}{lllr}
\hline Warm-up protocols & Gender & $M$ & $S D$ \\
\hline \multirow{3}{*}{ Greek traditional dance } & Male & 12.09 & .97 \\
\cline { 2 - 4 } & Female & 12.51 & 1.04 \\
\cline { 2 - 4 } & Total & 12.33 & 1.02 \\
\hline \multirow{3}{*}{ No stretching } & Male & 12.20 & .96 \\
\cline { 2 - 4 } & Female & 12.68 & 1.12 \\
\cline { 2 - 4 } & Total & 12.48 & 1.07 \\
\hline \multirow{3}{*}{ Dynamic stretching } & Male & 12.15 & .92 \\
\cline { 2 - 4 } & Female & 12.62 & 1.26 \\
\cline { 2 - 4 } & Total & 12.42 & 1.14 \\
\hline \multirow{2}{*}{ Static stretching } & Male & 12.34 & 1.04 \\
\cline { 2 - 4 } & Female & 12.91 & 1.25 \\
\cline { 2 - 4 } & Total & 12.66 & 1.19 \\
\hline
\end{tabular}

Mauchly's sphericity test showed that there is no significant statistical difference within variance $\left(X^{2}=.512, p=.992\right)$. According to the ANOVA results, there were no significant differences between the two genders $\left(F_{(1,42)}=2.881, p=.096\right)$. Moreover, there were no significant interactions between the warm-up protocols and gender $\left(F_{(3,126)}=.295, p=.828\right)$. However, the main effect of the warm-up protocols was statistically significant $\left(F_{(3,126)}=5.011, p=.002\right)$. According to the Bonferroni-test results the Greek-traditional-dance protocol displayed significantly better performance than the static-stretch protocol $(p=.012)$. 


\section{Long Jump Test}

Table 2 displays the mean scores $(M)$ and the standard deviation $(S D)$ for boys and girls regarding long jump.

Table 2. Mean scores $(\mathrm{cm})$ and standard deviation of the long jump tes

\begin{tabular}{llrr}
\hline Warm-up protocols & Gender & $M$ & $S D$ \\
\hline \multirow{4}{*}{ Greek traditional dance } & Male & 145.30 & .97 \\
\cline { 2 - 4 } & Female & 134.37 & 1.04 \\
\cline { 2 - 4 } & Total & 139.11 & 1.02 \\
\hline \multirow{3}{*}{ Dynamic stretching } & Male & 149.72 & .96 \\
\cline { 2 - 4 } & Female & 136.70 & 1.12 \\
\cline { 2 - 4 } No stretching & Total & 142.36 & 1.07 \\
\hline \multirow{3}{*}{ Static stretching } & Male & 144.18 & .92 \\
\cline { 2 - 4 } & Female & 131.73 & 1.26 \\
\cline { 2 - 4 } & Total & 137.13 & 1.14 \\
\hline & Male & 145.44 & 1.04 \\
\cline { 2 - 4 } & Female & 132.50 & 1.25 \\
\cline { 2 - 4 } & Total & 138.11 & 1.19 \\
\hline
\end{tabular}

Mauchly's sphericity test showed that there is no significant statistical difference within variance $\left(X^{2}=9.550, p=.080\right)$. There were no significant differences between the two genders, $\left(F_{(1,42)}=3.003, p=.070\right)$. Moreover, there were no significant in teractions between the warm-up protocols and gender $\left(F_{(3,126)}=\right.$ .227, $p=.877$ ). The main effect of the warm-up protocols was statistically significant $\left(F_{(3.126)}=5.043, p=.002\right)$. According to the Bonferroni-test results the dynamic stretching protocol displayed significantly better performance than the protocols of static stretching $(p=.017)$ and no stretching $(p=.001)$. There was no significant difference between dynamic stretching and the Greek traditional dance.

\section{Static Flexibility Test (Sit and Reach)}

Table 3 displays the mean scores $(M)$ and standard deviation $(S D)$ for boys and girls as far as the static flexibility test is concerned.

Table 3. Mean scores $(\mathrm{cm})$ and standard deviation of the static flexibility test

\begin{tabular}{lllr}
\hline Warm-up protocols & Gender & $M$ & $S D$ \\
\hline \multirow{3}{*}{ Static stretching } & Male & 25.54 & 6.86 \\
\cline { 2 - 4 } & Female & 29.26 & 7.21 \\
\cline { 2 - 4 } No stretching & Total & 27.65 & 7.23 \\
\hline & Male & 24.30 & 7.33 \\
\cline { 2 - 4 } & Female & 27.18 & 7.42 \\
\cline { 2 - 4 } & Total & 25.93 & 7.45 \\
\hline \multirow{3}{*}{ Dynamic stretching } & Male & 23.52 & 7.14 \\
\cline { 2 - 4 } & Female & 28.65 & 8.25 \\
\cline { 2 - 4 } & Total & 26.42 & 8.13 \\
\hline \multirow{3}{*}{ Greek traditional dance } & Male & 23.69 & 7.49 \\
\cline { 2 - 4 } & Female & 27.86 & 7.52 \\
\cline { 2 - 4 } & Total & 26.05 & 7.72 \\
\hline
\end{tabular}

Mauchly's sphericity test showed that there is no statistically significant difference within variance $\left(X^{2}=9.070, p=.067\right)$. According to the ANOVA results there were no significant interactions between the warm-up protocols and gender $\left(F_{(3,126)}=\right.$ $1.530, p=.209)$. However, there were significant differences between the two genders, $\left(F_{(1,42)}=4.131, p=.047\right)$ with girls performing statistically better in all protocols compared to boys. Furthermore, the main effect of the warm-up protocols was statistically significant, $\left(F_{(3,126)}=4.270, p=.006\right)$. According to the Bonferroni-test results the static stretching protocol displayed significantly better performance compared to no-strech ( $p=$ $.029)$ and the Greek-traditional-dance protocols $(p=.002)$.

Dynamic Flexibility

Table 4 displays the mean scores $(M)$ and standard deviation $(S D)$ for boys and girls as far as dynamic flexibility is concerned.

Table 4. Mean scores (degrees) and standard deviation (SD) of the dynamic flexibility

\begin{tabular}{lllr}
\hline Warm-up protocols & Gender & $M$ & $S D$ \\
\hline \multirow{4}{*}{ Static stretching } & Male & 105.09 & 9.67 \\
\cline { 2 - 4 } & Female & 104.39 & 8.18 \\
\cline { 2 - 4 } & Total & 104.70 & 8.78 \\
\hline \multirow{3}{*}{ Dynamic stretching } & Male & 105.30 & 8.14 \\
\cline { 2 - 4 } & Female & 105.20 & 5.07 \\
\cline { 2 - 4 } No stretching & Total & 105.24 & 6.51 \\
\hline \multirow{3}{*}{ Greek traditional dance } & Male & 105.24 & 7.80 \\
\cline { 2 - 4 } & Female & 104.29 & 8.09 \\
\cline { 2 - 4 } & Total & 104.70 & 7.91 \\
\hline & Male & 105.57 & 8.18 \\
\cline { 2 - 4 } & Female & 103.39 & 7.03 \\
\cline { 2 - 4 } & Total & 104.34 & 7.55 \\
\hline
\end{tabular}

Mauchly's sphericity test showed that there is no significant statistical difference $\left(X^{2}=9.751, p=.083\right)$. The main effect of the warm-up protocols was not statistically significant, $\left(F_{(3,126)}=\right.$ $.172, p=.915)$. There were no significant differences between the two genders, $\left(F_{(1,42)}=.335, p=.565\right)$. Moreover, there were no significant interactions between the warm-up protocols and gender, $\left(F_{(3,126)}=.325, p=.807\right)$.

\section{Discussion}

According to the findings, the traditional dance protocol showed statistically significant higher scores in agility compared to the static-stretch protocol. However, it did not display better scores in any of the other measurements. Hence, the question that arises from these findings is whether the Greek traditional dance should be used as a warm-up protocol. In order to give an answer to this, it is worth examining the findings in detail.

In terms of agility, it was expected that the dynamic-stretch protocol and the traditional dance would display better results. The mean scores confirmed this expectation. However, only the mean scores of the dance protocol displayed significantly better scores than the static protocol. The fact that there was no statistical difference between the static protocol and the dynamic protocol complies with the research by Faigenbaum et al. (2006) and Chaouachi et al. (2010). Chaouachi et al. (2010) attributed the lack of significant difference between these two protocols to the recovery time between the stretching and the measurements and considered that a shorter than 5-minute recovery time between the SS and the measurement had affected the results. For this reason, they suggest that the measurements take place at least 5 minutes upon completion of the static stretching (Chaouachi et al., 2010). Additionally, they agree with the research findings of Lykesas et al. (2003) in which a group of pre-school students, participants in organized after-school activities, displayed statistically significant differences in motor flexibility, fluency and originality, since they were participating in after-school activities. On the other hand, the findings of Mc Millian et al. (2006), Little et al., (2006), Van Gelder et al. (2011), and Chatzopoulos et al. (2014) do not coincide. The common characteristic of these studies is that their sample was teenage and adult athletes. Hence, the 
different results to this current research could be attributed to the early age of the sample and the fact that the children did not participate in after-school training at sports clubs.

According to the findings, the static-stretch protocol displayed significantly better performance than the dynamic-stretch and the Greek-traditional-dance protocols. The primacy of static stretching could be explained by the increase of the joints' amplitude of movement during static stretching (Young \& Behm, 2002). This finding coincides with those of Behm, et al. (2004), Paradisis et al. (2014), Mayorga-Vega et al. (2014), Chan et al. (2001), Davis et al. (2005), Bacurau et al. (2009) and Samson et al. (2012). However, there is also a category of research that has reported non-significant differences between static and dynamic stretching in terms of flexibility (Perrier et al., 2011). Another relevant research in children (Faigenbaum et al., 2005), under similar conditions to this one, showed that there were no differences between the protocols of static and dynamic stretching. The researchers assumed that the non-significant differences may have been caused by the time elapsed between the warm-up protocols' conduct and the flexibility test which was realized 20 to 25 minutes after the warmup exercises. Moreover, only the measurement of flexibility presented differences between the two genders, with girls displaying better results. This finding is in accordance with other similar research (Kubo et al., 2003). Women are usually more flexible than men, especially in lower extremities, due to the skeleton form of the pelvis. As girls approach adolescence they reach a level of flexibility that may be maintained or decreased during adulthood (Docherty \& Bell, 1985).

In terms of dynamic flexibility, there were no significant differences among the warm-up protocols. The results of this research comply with the research of Amiri- Khorasani et al. (2011), which presented the significant effect of dynamic stretching compared to the static one, as far as the dynamic warm-up of professional football players is concerned. It is possible that the difference in age and the experience of professional football players in this specific movement may have determined the difference in the results.

Finally, concerning the long jump there were significant differences between the dynamic-stretch protocol and the dance protocol but still not between the dynamic and static- stretch protocols. The last finding agrees with the corresponding results reported by Faigenbaum et al. (2005), who also conducted research in children. It does not agree though with the findings of the research by Behm and Chaouachi (2011), Alikhajeha (2012) and Andrejić (2012) that mention a significant difference between static and dynamic stretching. Fletcher's research (2010) on the effect of dynamic stretching on strength used different intensity protocols (low and high speed of performance) and reported that the high-intensity protocol displayed better results compared to the low-intensity protocol (Fletcher, 2010). It may, therefore, be useful for future research to study the factor of rhythm in the performance of dynamic stretching, in primary school students. The high-intensity protocol that was applied to trained adults may possibly be too tiring for untrained primary school students. Further study on this is needed as the overall research on the significant differences between static and dynamic stretching had male and female college students, who were training in several sports on a continuous and regular basis, as a sample. The sample of this current research was students of the fifth and the sixth grade of a primary school and none of them was working out systematically. According to Magnusson et al. (1994), adults who train actively respond differently to static stretching compared to minors. This is due to the toughening of the muscle-tendon unit and the age-related decrease of its flexibility (Magnusson et al., 1994). It would be interesting for future research to study the effect of warm-up protocols on a group of children who follow an intense and diverse after-school sports training, as well as, to compare these results to those of children who do not follow an additional extra-curricular training.

Apart from the level of training, the age of the sample could have also influenced the non-significant difference between dynamic and static stretching in the long jump. The effect of static stretching on children may be different from that on adults. Adults present lower flexibility compared to children due to calcium deposition, toughening of the joints, and the different composition of muscle fibers from adipose and collagen fibers (Holloszy et al., 1995).

\section{Concluding Remarks}

In conclusion, based on the research results, the warm-up with static stretching presents a positive effect on static flexibility so its use prior to exercises of artistic and rhythmic gymnastics is highly recommended. As for team sports like basketball, volleyball, handball, and football, which are key elements of the school subject of physical education, both protocols of static stretching and Greek traditional dance may be incorporated and used, in terms of agility and dynamic flexibility, as, according to this study, there was no significant statistical difference between them. Overall, relevant data for the warm-up of children arise from this study that could be valuable to primary school PE teachers and coaches who work with children, and they may contribute to further improve the quality of the lesson.

\section{References}

Adam, C., Klissouras, V., Ravazollo, M., Renson, R., \& Tuxworth, W. (1988). Eurofit: European test of Physical Fitness. Council of Europe, Committee for the Development of Sport.

Alikhajeh, Y. (2012). The Effect of Different Warm-Up Protocols on Young Soccer Players' Explosive Power. Procedia-Social and Behavioral Sciences, 46, 2742-2746.

Alikhajeh, Y., Rahimi, N. M., Fazeli, K., \& Fazeli, H. (2012). The effect of different warm up stretch protocols on $20 \mathrm{~m}$-sprint performance in trained soccer players. Procedia-Social and Behavioral Sciences, 46, 210-2214.

Amiri-Khorasani, Mohammadtaghi, Noor A. Abu Osman, and Ashril Yusof. (2011). Acute effect of static and dynamic stretching on hip dynamic range of motion during instep kicking in professional soccer players. The Journal of Strength \& Conditioning Research, 25(6), 647-1652.

Andrejić, O. (2012). An investigation into the effects of different warm-up protocols on flexibility and jumping performance in youth. Facta universitatis-series: Physical Education and Sport, 10(2), 107-114.

Bacurau, R. F. P., Monteiro, G. A., Ugrinowitsch, C., Tricoli, V., Cabral, L. F., \& Aoki, M. S. (2009). Acute effect of a ballistic and a static stretching exercise bout on flexibility and maximal strength. The Journal of Strength \& Conditioning Research, 23(1), 304-308.

Behm D. G. \& Chaouachi A. (2011). review of the acute effects of static and dynamic stretching on performance. Eur J Appl Physiol, 111, 2633-2651.

Behm, D. G., Bambury, A., Cahill, F., \& Power, K. (2004). Effect of acute static stretching on force, balance, reaction time, and movement time. Medicine and Science in Sports and Exercise, 36, 1397-1402. 
Bishop, D. (2003). Warm up I. Sports Medicine, 33(6), 439-454.

Bishop, D., \& Middleton, G. (2013). Effects of static stretching following a dynamic warm-up on speed, agility and power. Journal of Human Sport and Exercise, 8(2), 391400.

Bosco C., Tarkka I., \& Komi PV. (1982). Effect of elastic energy and myoelectrical potentiation of triceps surae during stretch shortening -cycle exercise. International Journal of Sports Medicine, 3(3), 137-140.

Chan, S. P., Hong, Y., \& Robinson, P. D. (2001). Flexibility and passive resistance of the hamstrings of young adults using two different static stretching protocols. Scandinavian Journal of Medicine \& Science in Sports, 11(2), 81-86.

Chaouachi, A., Castagna, C., Chtara, M., Brughelli, M., Turki, O., Galy, O. ... \& Behm, D. G. (2010). Effect of warm-ups involving static or dynamic stretching on agility, sprinting, and jumping performance in trained individuals. The Journal of Strength \& Conditioning Research, 24(8), 2001-2011.

Chatzopoulos, D., Doganis, G., Lykesas, G., Koutlianos, N., Galazoulas, C., \& Bassa, E. (2019). Effects of Static and Dynamic Stretching on Force Sense, Dynamic Flexibility and Reaction Time of Children. The Open Sports Sciencew Journal, 12(1), 22-27.

Chatzopoulos, D., Galazoulas, C., Patikas, D., \& Kotzamanidis, C. (2014). Acute effects of static and dynamic stretching on balance, agility, reaction time and movement time. Journal of Sports Science \& Medicine, 13(2), 403409.

Chatzopoulos, D., Yiannakos, A., Kotzamanidou, M., \& Bassa, E. (2015). Warm-up protocols for high school students. Perceptual and Motor Skills, 121(1), 1-13.

Coledam, D. H. C., Paludo, A. C., De Oliveira, A. R., \& Dos-Santos, J. W. (2012). Dynamic exercise versus tag game warm up: The acute effect on agility and vertical jump in children. Journal of Human Sport and Exercise, 7, 243253.

Davis, D. S., Ashby, P. E., McCale, K. L., McQuain, J. A., \& Wine, J. M. (2005). The Effectiveness of 3Stretching Techniques on Hamstring Flexibility Using Consistent Stretching Parameters. The Journal of Strength \& Conditioning Research, 19(1), 27-32.

Docherty, D., and Bell D. R. (1985). The relationship between flexibility and linearity measures in boys and girls 6-15 years of age. Journal of Human Movement Studies, 11(5), 279-288.

Faigenbaum, A. D., Bellucci, M., Bernieri, A., Bakker, B., \& Hoorens, K. (2005). Acute effects of different warm-up protocols on fitness performance in children. The Journal of Strength \& Conditioning Research, 19(2), 376-381.

Faigenbaum, A. D., Kang, J., McFarland, J., Bloom, J. M., Magnatta, J., Ratamess, N. A., \& Hoffman, J. R. (2006). Acute effects of different warm-up protocols on anaerobic performance in teenage athletes. Pediatric Exercise Science, 17, $64-75$.

Fletcher, I. M. (2010). The effect of different dynamic stretch velocities on jump performance. European Journal of Applied Physiology, 109(3), 491-498.
Gelen, E. (2011). Acute effects of different warm-up methods on jump performance in children. Biology of Sport, $28(2), 133-138$

Hedrick, A. (2000). Dynamic Flexibility Training. Strength \& Conditioning Journal, 22(5), 33-38.

Holloszy, J. O., Faulkner, J. A., Brooks, S. V., \& Zerba, E. (1995). Muscle atrophy and weakness with aging: contraction-induced injury as an underlying mechanism. Journals of Gerontology Series A: Biological Sciences and Medical Sciences, 50, 124-129.

Koutedakis Y., Clarke, F., Wyon, M., Aways, D., Owolabi, O.E. (2009). Muscular Strength: Applications for Dancers. Med Probl Perform Art, 24, 157-165.

Kubo, K., Kanehisa, H., \& Fukunaga, T. (2003). Gender differences in the viscoelastic properties of tendon structures. European Journal of Applied Physiology, 88(6), 520-526.

Lee, S. M., Burgeson, C. R., Fulton, J. E., \& Spain, C. G. (2007). Physical education and physical activity: results from the School Health Policies and Programs Study 2006. Journal of School Health, 77(8), 435-463.

Lima, C. D., Brown, L. E., Ruas, C. V. \& Behm, D. G. (2018) Effects of Static Versus Ballistic Stretching on Hamstring:Quadriceps Strength Ratio and Jump Performance in Ballet Dancers and Resistance Trained Women. Journal of Dance Medicine Science, 22(3), 160-167.

Little, T., \& Williams, A. G. (2006). Effects of differential stretching protocols during warm-ups on high-speed motor capacities in professional soccer players. The Journal of Strength \& Conditioning Research, 20(1), 203-307.

Lykesas, G., Thomaidou, E., Tsobanaki, Th., Papadopoulou, S. Tsapakidou, A. (2003). Development of motor flexibility - flexibility and originality through creative movement in Kindergarten. Inquiries in Sport \& Physical Education, 1(3), 211-220.

Lykesas, G., Tsapakidou, A. \& Tsompanaki, E. (2016). Creative Dance as a Means of Growth and Development of Fundamental Motor Skills for Children in First Grades of Primary Schools in Greece. Asian Journal of Humanities and Social Studies, 2(1), 211-218.

Magnusson, M.,.Johansson, K. \& Johansson,B.B. (1994). Sensory stimulation promotes normalization of postural control after stroke. Stroke, 25, 1176-1180.

Mayorga-Vega, D., Merino-Marban, R., Sánchez-Rivas, E., \& Viciana, J. (1994). Effect of a short-term static stretching training program followed by five weeks of detraining on hamstring extensibility in children aged 9-10 years. Journal of Physical Education \& Sport, 14(3), 355-359.

McMillian, D. J., Moore, J. H., Hatler, B. S., \& Taylor, D. C. (2006). Dynamic vs. static-stretching warm up: the effect on power and agility performance. The Journal of Strength \& Conditioning Research, 20(3), 492-499.

McNeal, J. R., \& Sands, W. A. (2003). Acute static stretching reduces lower extremity power in trained children. Pediatric Exercise Science, 15(2), 139-145.

Morrin, N. \& Redding, E. (2013). Acute effects of warm-up stretch protocols on balance, vertical jump height, and range of motion in dancers. Journal of Dance Medicine Science, 17(1), 34-40. 
Paradisis, G.P., Pappas, P.T., Theodorou, A.S., Zacharogiannis, E.G., Skordilis, E.K. \& Smirniotou, A. (2014). Effects of static and dynamic stretching on sprint and jump performance in boys and girls. The Journal of Strength \& Conditioning Research, 28(1), 154-160.

Perrier, E. T., Pavol, M. J., \& Hoffman, M. A. (2011). The acute effects of a warm-up including static or dynamic stretching on countermovement jump height, reaction time, and flexibility. The Journal of Strength \& Conditioning Research, 25(7), 1925-1931.

Ruiz J.R., Ortega F.B., Gutierrez A., Meusel D., Sjöström M., Castillo M. J. (2006). Health-related fitness assessment in childhood and adolescence: a European approach based on the AVENA, EYHS and HELENA studies. Journal Public Health, 14, 269-277.

Samson, M., Button, D. C., Chaouachi, A., \& Behm, D. G. (2012). Effects of dynamic and static stretching within general and activity specific warm-up protocols. Journal of Sports Science \& Medicine, 11(2), 279-285.

Shellock, F. G., \& Prentice, W. E. (1985). Warming-up and stretching for improved physical performance and prevention of sports-related injuries. Sports Medicine, 2(4), 267-278.

Sofianidis, G., Hatzitaki, V., Douka, St. \& Grouios, G. (2009). Effect of a 10-Week Traditional Dance Program on Static and Dynamic Balance Control in Elderly Adults. Journal of Ageing and Physical Activity, 17(2), 167-180.

Sofianidis, G., Hatzitaki, V., Douka, St. \& Grouios, G. (2009). Effect of a 10-Week Traditional Dance Program on Static and Dynamic Balance Control in Elderly Adults. Journal of Ageing and Physical Activity, 17(2), pp. 167-180.

Troumbley, P. (2010). Static Versus Dynamic Stretching Effect on Agility Performance. (P. E. Unpublished Thesis in Health, Ed.) Utah, USA: Utah State University.

Turki, O., Chaouachi, A., Drinkwater, E. J., Chtara, M., Chamari, K., Amri, M., \& Behm, D. G. (2011). Ten minutes of dynamic stretching is sufficient to potentiate vertical jump performance characteristics. The Journal of Strength \& Conditioning Research, 25(9), 2453-2463.

Van Gelder, L. H., \& Bartz, S. D. (2011). The effect of acute stretching on agility performance. The Journal of Strength \& Conditioning Research, 25(11), 3014-3021.

Venetsanou, F. \& Kambas, A. (2010). How can a traditional Greek dances programme affect the motor proficiency of pre-school children? Research in Dance Education, 5(2), pp. 127-138.

Winchester, J. B., Nelson, A. G., Landin, D., Young, M. A., \& Schexnayder, I. C. (2008). Static stretching impairs sprint performance in collegiate track and field athletes. The Journal of Strength \& Conditioning Research, 22(1), 13-19.

Yamaguchi, T., \& Ishii, K. (2005). Effects of static stretching for 30 seconds and dynamic stretching on leg extension power. The Journal of Strength \& Conditioning Research, 19(3), 677-683.
Ylinen, J. J., Kautiainen, H. J., \& Häkkinen, A. H. (2010). Comparison of active, manual, and instrumental straight leg raise in measuring hamstring extensibility. The Journal of Strength \& Conditioning Research, 24(4), 972-977.

Young, W. B., \& Behm, D. G. (2002). Should Static Stretching Be Used During a Warm-Up for Strength and Power Activities? Strength \& Conditioning Journal, 24(6), 3337. 